\title{
A review of maintenance service for leasing equipment
}

\author{
N Kurniati ${ }^{*}$, E Widodo ${ }^{1}$, A Supriatna ${ }^{1}$, C Lestari ${ }^{1}$ \\ ${ }^{1}$ Department of Industrial Engineering, Institut Teknologi Sepuluh Nopember, \\ Surabaya, Indonesia \\ *nanikur@ie.its.ac.id
}

\begin{abstract}
Recent business trend focuses more on efficiency. One of the chosen ways is leased the capital equipment from other parties. The leasing option encourages both the lessee and lessor to discuss any consequences include responsibility for managing the equipment performance, rectifying failure during operation, maintenance option provided during leasing period, as well as the accompanying cost. The review and maping of publications are conducted based on the order in which the reference appears in the publication, in order to follow the development of thinking on the research topic of leasing, yet to identify the more recent development during the last decade. Several potential research ideas could be generated from the maping toward the fast and flexibel business
\end{abstract}

\section{Introduction}

Under the current business with high viable markets, company may need to focus on its core business, but keeping its supporting function runs well. Considering the efficiency in all business aspects may drive the company to share the equipment as well as other resources. They may divert all or some portion of its responsibility to the other company which has more expertise on it. Other reasons that worth by company is relate with finance issue include tax saving, reducing investment risk and working capital due to the expensive purchase cost (1).

The current fast improvement in innovation technology, advance complexity of products / equipment, enforced the requirement of professional technicians to maintain the equipment; hence, the maintenance cost is getting higher, which is not economical for company (2). Therefore, companies trend to lease (rent) the equipment instead of possess it.

Under such arrangement, lessor, owns the equipment and leases it to another company i.e. lessee, who uses it and gets the benefit for their core business or supporting the core business. For that reasons, the lessor offers the equipment as well as its maintenance services, while lessee pay the leased equipment. The interaction between lessor and lessee provides in Figure 1. A contractual leasing agreement (leasing contract) then signed by those two, usually contain information about equipment specific length of the lease period, the rent and the penalty clauses. The penalty clauses usually determine that the lessor would be penalized when the leased equipment could not carry out its intended performance according to the agreed-predetermined purpose. The lessor responsible to provide maintenance services during the leasing period. Many option of maintenance policy could be taken by lessor. In general, there are two types of maintenance are considered within the lease periods i.e. correctie maintenance (CM) and preventive maintenance (PM). CM actions are used to rectify equipment failure and restore it back to 
operational state. PM actions more concern to improve the equipment's operational state to avoid failures.

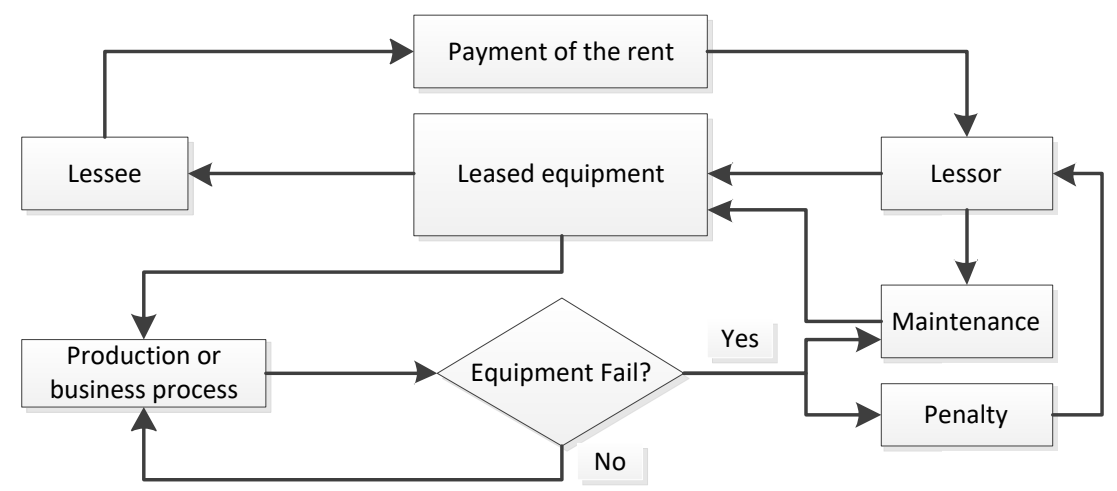

Figure 1. System characteristics for leasing equipment

\section{Maintenance Policy}

Maintenance, generally has two impacts i.e. to improve machine reliability and tensures continuity of production/business process. However, maintenance activities result an additional cost for company about $15-40 \%$ of total production costs, include maintenance task, labor cost, spare parts, and other (3). Even any failures rectified by conducting corrective maintenance, such problems may effect e.g. production process disruption, operator safety and damage issues (4). Swanson explains, Maintenance contribute to extending the effective operational system lifetime, improve reliability and system availability. The scope of this maintenance is a service routine and periodic inspections, preventive replacement, condition monitoring, work planning, purchasing and material management, personnel management, and quality control.

Lot of literatures are available from various resources in the field of maintenance management. Grag and Desmukh (5) have presented various classifications of maintenance optimization models by analyzing 142 papers. A broad classification of these literatures can be devided in to six areas: maintenance optimization models, maintenance techniques, maintenance scheduling, maintenance performance measurement, maintenance information systems; and maintenance policies.

The evolution of maintenance performance measurement, related to maintenance organizational function, resource utilization, activities and practices are provided by (6). Ding and Komarudin (7) have initiated survey and attempted to categorize the optimization of maintenance policy model based on three degree: certain, risk, and uncertain. Maintenance strategy may also choose by considering the object characteristics. The chosen strategy affects the maintenance schedule, costs, personnel requirements, etc. Therefore, optimal maintenance strategy may determine by consider certain criteria. The optimal preventive maintenance policy may weight the result of activity in terms of costs and determination methods for reliability. The solution of optimization model may involve analytic model or heuristic models. Basically, there are two different approaches for maintenance option i.e. time-based maintenance (TBM) and condition based maintenance (CBM).

\section{Maintenance Policy for Leased Equipment}

For repairable leased equipment, there are two types of maintenance policy may applied, corrective maintenance (CM) and preventive maintenance (PM) with different basic purpose. Corrective action apply whenever equipment experience on failure, so rectification action needed to bring back the 
equipment to its operational state. While preventive action is performed to improve and keep the performance of equipment on its operational state in order to prevent failures. Maintenance task may choose in corrective action, minimal repair is the commonly used task to employ. After the minimal repair task, the equipment is under normal operation but the failure rate remains unchanged [8][9].

Lessor has responsibility to maintain the equipment performance as predetermined in leasing contract, otherwise penalty may apply. Papers discussed leasing equipment system and its optimal maintenance policy described in (1,2,8-14). Most of those papers consider repair time (except (15)) and applied two policies; minimal repair for taking back the machine to its operational states, and imperfect PM to prevent failure. However, (10) used periodic imperfect PM for as good as new condition with probability $p$ and keep its as bad as old condition with probability $q$. Whenever failure happened will rectify using imperfect repair that following decreasing quasi-renewal process for its efficiency measure.

PM can be classified into two major categories, perfect PM and imperfect PM (16) based on the condition of failure rate after PM. Describing the PM degree can be identified using two different methods i.e. age reduction method (ARM) and failure rate reduction method (FRRM). ARM employ to keep the equipment with performance as good as the younger age, while FRRM more focus on reducing equipment's failure rate. Pongpech \& Murthy (8) utilized FRRM and derived the optimal PM policy for leased equipment. Some other issues associated with FRRM can be found in the literature $(10,14)$. Yeh et al. (11) utilized ARM to describe PM degree and derived the optimal PM policy for leased equipment with considering lease period extension at the beginning of the contract. Some other issues associated with ARM can be found in the literatures $(1,13,14)$.

Most studies mentioned focus on determining the optimal PM policy with a specified lease period by minimizing cost, or an extension of lease period that was offered at the begin of the contract by maximizing profit. In terms of optimization, different criteria may apply. Papers no $(8,9,13,14)$ apply minimum lessor's cost, while $(1,5)$ prefer to maximize the profit, which not only consider cost but also revenue.

In terms of leased period, papers number $(1,8,9,13,14)$ use predetermined (base) leased period. The extension of leasing period may offer to the lessee both offered at the beginning of the contract period as proposed by (11). On the other hand, other paper studied the extension period from other filed of research. Chang \& Lin (17) used ARM to derive the optimal PM policy for the length of warranty extension after the base warranty period expires. Thus, extension of the lease period after base lease period ends may be a critical issue to get more benefit for the lessor and the lessee.

Research could be made by taking an analogy from other research. For instance, an extended period may apply in warranty as well as in leased. The extended warranty offer by (11) at the time of base warranty ended. Therefore, the extended leased period may also offer at the time of leased base period terminated. Some advantages include reducing lessee's financial risk for leasing period extension e.g. machine performance uncertainty, lessor's responsibility, etc. Lessor may offer discount to the lessee for those extension. Research may differ from (11) by considering time duration of minimal repair and lessor will suffer penalty cost if the equipment fail.

\section{References}

1. Chang WL, Lo H-C. Joint determination of lease period and preventive maintenance policy for leased equipment with residual value. Comput Ind Eng. 2011 Oct 1;61(3):489-96.

2. Yeh RH, Chang WL. Optimal threshold value of failure-rate for leased products with preventive maintenance actions. Math Comput Model. 2007 Sep 1;46(5-6):730-7.

3. Mobley RK. An introduction to predictive maintenance. New York NY: Van Nostrand Reinhold; 1990. 189 p.

4. Parida A, Kumar U. Maintenance Productivity and Performance Measurement. In: Handbook of 
Maintenance Management and Engineering. London: Springer London; 2009. p. 17-41.

5. Garg A, Deshmukh SG. Maintenance management: literature review and directions. J Qual Maint Eng. 2006 Jul 12;12(3):205-38.

6. Simões JM, Gomes CF, Yasin MM. A literature review of maintenance performance measurement. J Qual Maint Eng. 2011 May 31;17(2):116-37.

7. Ding S-H, Kamaruddin S. Maintenance policy optimization-literature review and directions. Int J Adv Manuf Technol. 2015 Feb 16;76(5-8):1263-83.

8. Pongpech J, Murthy DNP. Optimal periodic preventive maintenance policy for leased equipment. Reliab Eng Syst Saf. 2006 Jul 1;91(7):772-7.

9. Jaturonnatee J, Murthy DNP, Boondiskulchok R. Optimal preventive maintenance of leased equipment with corrective minimal repairs. Eur J Oper Res. 2006 Oct 1;174(1):201-15.

10. Yeh RH, Kao K-C, Chang WL. Optimal preventive maintenance policy for leased equipment using failure rate reduction. Comput Ind Eng. 2009 Aug 1;57(1):304-9.

11. Yeh RH, Chang WL, Lo H-C. Optimal length of lease period and maintenance policy for leased equipment with a control-limit on age. Math Comput Model. 2011 Nov 1;54(9-10):2014-9.

12. Schutz J, Rezg N. Maintenance strategy for leased equipment. Comput Ind Eng. 2013 Nov 1;66(3):593-600.

13. Zhou X, Li Y, Xi L, Lee J. Multi-phase preventive maintenance policy for leased equipment. Int J Prod Res. 2015 Aug 3;53(15):4528-37.

14. Ben Mabrouk A, Chelbi A, Radhoui M. Optimal imperfect maintenance strategy for leased equipment. Int J Prod Econ. 2016 Aug 1;178:57-64.

15. Nakagawa T. A summary of periodic replacement with minimal repair at failure. J Oper Res Soc Japan. 1981;24(3):213-27.

16. Jack N, Murthy DNP. A flexible extended warranty and related optimal strategies. J Oper Res Soc. 2007 Dec 21;58(12):1612-20.

17. Chang WL, Lin J-H. Optimal maintenance policy and length of extended warranty within the life cycle of products. Comput Math with Appl. 2012 Jan 1;63(1):144-50.

\section{Acknowledgements}

This work was partially supported by the Research and Community Service Institution, Institut Teknologi Sepuluh Nopember (ITS) under 2017 ITS Local Funding Program [grant number 1174/PKS/ITS/2017 